\title{
Article
}

\section{The experience of Colombian boys and young men living with Duchenne muscular dystrophy}

\author{
Ximena Palacios-Espinosa ${ }^{\mathrm{a}^{*}}$ \\ Heidi Mateus ${ }^{b}$ (B) \\ Martha Dávalos ${ }^{\mathrm{a}}$ (i) \\ Jennifer Gracia ${ }^{\mathbb{C}}$ \\ Hamer Bastidas-Bilbao a* \\ a School of Medicine and Health Sciences, Universidad del Rosario, Bogotá, Colombia \\ ${ }^{b}$ Center for Research in Genetics and Genomics CIGGUR and GENIUROS research group. School \\ of Medicine and Health Sciences, Universidad del Rosario, Bogotá, Colombia
}

\begin{abstract}
Duchenne muscular dystrophy (DMD) is a chronic disease that primarily affects males and is characterized by progressive physical impairment and, eventually, death. This qualitative study aimed to explore and understand the experience of diagnosis and disease in young people with DMD living in Bogotá, Colombia. After securing approval from the Research Ethics Committee (CEI-ABN026-000311), nine individuals took part of a semi-structured interview, and their narratives were analyzed using thematic analysis. The main topics developed throughout the narratives were: negative representation of the disease; fear; difficulty expressing emotions; the patient-doctor relationship; the wheelchair; the caregivers and coping strategies. We conclude that young people affected by DMD face several challenging experiences that underscore the need for better, more respectful, and compassionate interactions with healthcare providers. Also, their experiences are indicative of a socio-cultural context that needs to become more responsive and compassionate towards young people and disability.
\end{abstract}

Keywords: Duchenne muscular dystrophy, children, adolescents, psychology, psychosocial aspects.

Duchenne Muscular Dystrophy (DMD) is an $\mathrm{X}$-linked disease that causes progressive irreversible muscle degeneration with an estimated incidence of about 1 in 3,800-6,300 live male births (Landfeldt et al., 2020). Currently, the global prevalence of DMD is estimated at 7.1 cases $(95 \%$ CI: $5.0-10.1)$ per 100,000 men. In the general population, the prevalence is 2.8 cases (95\%CI: $1.6-4.6)$ per 100,000 inhabitants. As for live-born males, the pooled prevalence is 19.8 (95\%CI: 16.6-23.6) in 100,000 (Crisafulli et al., 2020). DMD is also considered a rare disease with a prevalence of or under 1 per 2,000 people (Orphanet, 2012). Due to its inheritance pattern, males are the most affected, while females (mothers) are the carriers. Female carriers show no evidence of muscular weakness. However, cases of symptomatic female carriers have been reported (Giliberto et al., 2014; Fraser, Redmond, \& Scotcher, 2018), but are considered rare (Genetic and Rare Diseases Information Center, 2020).

Although the disease is present since birth, its symptoms appear at early childhood. The natural disease progression leads to muscle degeneration until males die in their youth. DMD begins with gait disturbance between the ages of two and five. This disturbance

* Corresponding address: hamerbilbao@gmail.com usually manifests itself as muscle weakness resulting in difficulty to run and climb stairs, and the occurrence of frequent falls. Consequently, children see themselves unable to keep up with peers in daily activities and playing. The loss of muscle strength progresses even further, and boys become permanent wheelchair users by the age of 12 (Desguerre \& Laugel, 2015). They often die of respiratory or heart failure in their late teens or early twenties (Rall \& Grimm, 2012), although, mechanical ventilation has increased their life expectancy (Yamaguchi, Sonoda, \& Suzuki, 2017).

In addition to motor impairment and, eventually, cognitive impairment (Di Filippo, Parisi, \& Roccella, 2012), a significant psychological burden is experienced by boys and young men affected by DMD, and also by their caregivers. Stress is a common response that increases on par with the disease progression (Nereo \& Hinton, 2003; Gocheva et al., 2019). Caregiving itself has psychological and physical consequences for people with the disease and their caregivers (Nereo, Fee, \& Hinton, 2003; Yamaguchi et al., 2017). Learning to live with a degenerative chronic disease like DMD remains a challenge for these individuals due to their loss of independence and the diminishment of several abilities and organic functions (Crivello, 2013). These losses, and the subsequent changes in daily living habits and 
social relationships, lead children into feeling worry, helplessness, shame, fear, resentment, and discomfort, which are emotions that contribute to the development of depressive and anxiety disorders that, in turn, have an additional impact on their quality of life (Crivello, 2013; Montalvo-Prieto, Cabrera-Nanclares, \& Quiñones-Arrieta, 2012; Velázquez Pérez \& Espín Andrade, 2014).

Physical impairment is one of many challenges faced by young people with DMD. Connors and Stalker conducted a survey of 26 disabled children and adolescents aged between 7 and 15 years, and found that their experience of disability comprised impairment, awareness of being different, reactions and behaviors of other people towards them, and physical barriers in their environments (Connors \& Stalker, 2007). Moreover, participants expressed that their disease was more salient when they considered the negative impact it brought upon their daily living routines (Connors \& Stalker, 2007).

Disability and impairment affect lifestyle and family dynamics. Consequently, they transform the family members' roles, tasks, and routines (Montalvo-Prieto et al., 2012; Montero Pardo, Jurado Cárdenas, \& Méndez Venegas, 2014). Specifically, children see their caregivers trying to facilitate their adjustment by being overprotective and solving their problems. On the other hand, adolescents experience frustration out of the changes in everyday life and the difficulties encountered when pursuing their life goals and plans.

This uncertainty about the future is a common element among adolescents with DMD and their families (Montalvo-Prieto et al., 2012), in addition to the stress and anxiety experienced by caregivers and other family members (Montero Pardo et al., 2014; Velázquez Pérez \& Espín Andrade, 2014). Caregivers play a fundamental role in coping with the disease. They are the main source of information for children about the etiology of the disease (Crivello, 2013). In fact, caregivers provide common explanations of disability, i.e.: (1) the child is special; (2) the disease is part of God's plan for the family; (3) the disease is a result from some sort of "accident" during birth, or from a family disease. In other cases, families will share medical explanations previously learned while receiving health services and, in other cases, they might avoid talking about the disease (Connors \& Stalker, 2007) or even hide information about what is happening despite the children's own expectations (Gargiulo et al., 2008). However, at a very early age, boys can identify that something is happening to their body and, at the same time, symptoms become increasingly evident and contribute to the development of a new disease awareness (Gargiulo et al., 2008). All of this elicits a variety of appraisals and emotions that change and evolve over time (Debarge, Delion, Cuisset, \& Réveillère, 2008; Gocheva, et al., 2019). At the same time, boys, and young men with DMD listen to, gather information, and communicate their experiences with the disease, and find different ways of expressing their suffering. Furthermore, they create their own individual understanding of the disease. These and many other aspects are the motivator behind this qualitative, descriptive, and interpretative study (Riger \& Sigurvinsdottir, 2016), situated in a theoretical framework of health psychology, aiming to explore the experiences of young people living with DMD. We also intend to highlight the role that qualitative research has played in the field of Health Psychology in recent decades due to its pertinence and contributions to understand the experience of individuals facing illness, as in the case of DMD (Murray \& Chamberlain, 1999; Chamberlain \& Murray, 2017).

\section{Method}

\section{Participants}

Nine boys and young men aged between 9 and 21 years, who have been previously diagnosed with DMD, participated in this study. All of them were joined by at least one caregiver and, most of them, used a wheelchair due to mobility issues. Most of the participants came from medium-low socioeconomic level households and were not attending school by decision of their caregivers. Most of them were also members of a non-profit foundation for individuals living with muscular dystrophy. This foundation was contacted by the lead researcher to secure collaboration in disseminating invitations to participate in this study. Other potential participants were active clients of specialized practices in genetics and psychology, where invitations to participate in this research were extended too. In each case, all the participants, and their parents or legal guardians, received detailed information about the nature of the study, its purposes, risks, and benefits. Questions were answered, and information was clarified when necessary. As required by local regulations, parents and/or legal guardians also granted authorization to conduct a cognitive assessment of their children before obtaining assent from them. Indicators of cognitive deficit were not used as exclusion criteria.

Convenience sampling was used, and sampling ended when the data reached a saturation point. Saturation was understood by the researchers as the moment in which no new categories were emerging from the ongoing collection of data (Urquhart, 2013) because of "informative redundancy", as described by Sandelowski (2008, p. 875). Also, given the inductive nature of this study, researchers were not able to propose a predefined set of categories (Sim, Saunders, \& Waterfield, 2018). Furthermore, considering the limited number of potential participants for this study - given the actual occurrence of the 
phenomenon of interest itself -, it was necessary to inform sampling decisions by using the saturation notions mentioned above (Fusch \& Ness, 2015). These sampling procedures were also evaluated and approved by the Research Ethics Committee.

\section{Procedures}

This study was submitted to and assessed by the Universidad del Rosario's Research Ethics Committee of the School of Medicine and Health Sciences. Authorization to conduct this study was granted upon careful consideration of compliance with ethical principles and local regulations. This authorization was issued under Decision Letter ID number CEI-ABN026-000311.

In order to gather data, participants provided informed consent before taking part in a semi-structured interview. Most participants were under legal age. Thus, information on the nature of participation was provided to them and to their parents, and an assent was obtained, as well as written consent from parents or legal guardians. Interviews were held in a private setting, with one or two interviewers, and lasted between 40 to 60 minutes. Parents or legal guardians of the participants were not present while their children were interviewed. Data collection was carried out for a period of two months.

\section{Data analysis}

Interviews were analyzed using thematic analysis. This method was chosen because of its value in the field of Health Psychology and its pertinence to identify, analyze, and communicate about the experiences narrated by our participants. We also adopted an inductive approach to thematic analysis with no predefined theoretical interests of our own (Braun \& Clarke, 2006).

Once data collection finished, interviews were transcribed and data were initially explored with the purpose of gaining an increased familiarity with the information, as indicated by Braun and Clarke (2006). Later, interviews were read several times looking for patterns related to specific interpretations used to devise an initial set of codes.

Secondly, the initial codes were contrasted against the data, which resulted in a second set of derived codes. These codes were analyzed and linked to the most relevant data emerging from the interviews. Then, a set of themes was derived from the final codes. Finally, relevant and salient themes were articulated and represented by a diagram structure. At the center of each diagram, we identified one main theme - represented by a circleand its branches represent connections to descriptors of the experience narrated by the participants the latter ones illustrated, in turn, by white boxes -.
In some cases, main themes derived into secondary and closely related themes - represented by shadowed boxes before connecting to the descriptors contained in the participants' narratives.

\section{Instruments}

For this study, a semi-structured interview was created. To identify and formulate the interview questions, the research team gathered to reflect and discuss broad topics on DMD and disability that could engage the participants with the interview and facilitate sharing of some elements of their experiences. During this encounter, the research team proposed several questions and chose 14 that to the best of their judgement - did not suggest or induce answers and were directed to exploring relevant aspects of the experience of living with a rare and degenerative disease in the local context.

Interviewers asked participants the following questions: (1) Do you know the name of your disease? (2) Who told you that? (3) For how long have you known about your disease? (4) When I say Duchenne Muscular Dystrophy, what other words go through your mind? (5) What is it like to live with this disease? (6) What is the most difficult part of living with this disease? (7) What scares you the most of this disease? (8) Why do you think you have this disease? (9) Who takes care of you? (10) How is your relationship between you and -name of the caregiver-? Why is that relationship the way you described it? (11) What is the best part of being cared for by -name of the caregiver-? (12) What bothers you the most of being cared for by -name of the caregiver-? (13) How is your relationship with your doctors? Why is that? (14) If you felt sad because of being sick or if you had any questions about your disease, who would you talk to?

Generally, the interview process was administered in three stages: 1) the interviewers introduced themselves and expressed a non-judgmental disposition to listen to the participants' narratives; 2) Interview questions; 3) Closure: each participant was offered the option of providing further information or details on their illness or on the interview process itself. Interviewers also asked participants about their age and their enrollment status at schools or other formal educational institutions.

\section{Results}

After analyzing the information obtained from the interviews, a thematic network was elaborated (Figure 1). This network depicts the most salient aspects of the experience of these boys and young men diagnosed with DMD. We also propose a narrative structured around the themes identified in the analysis. 


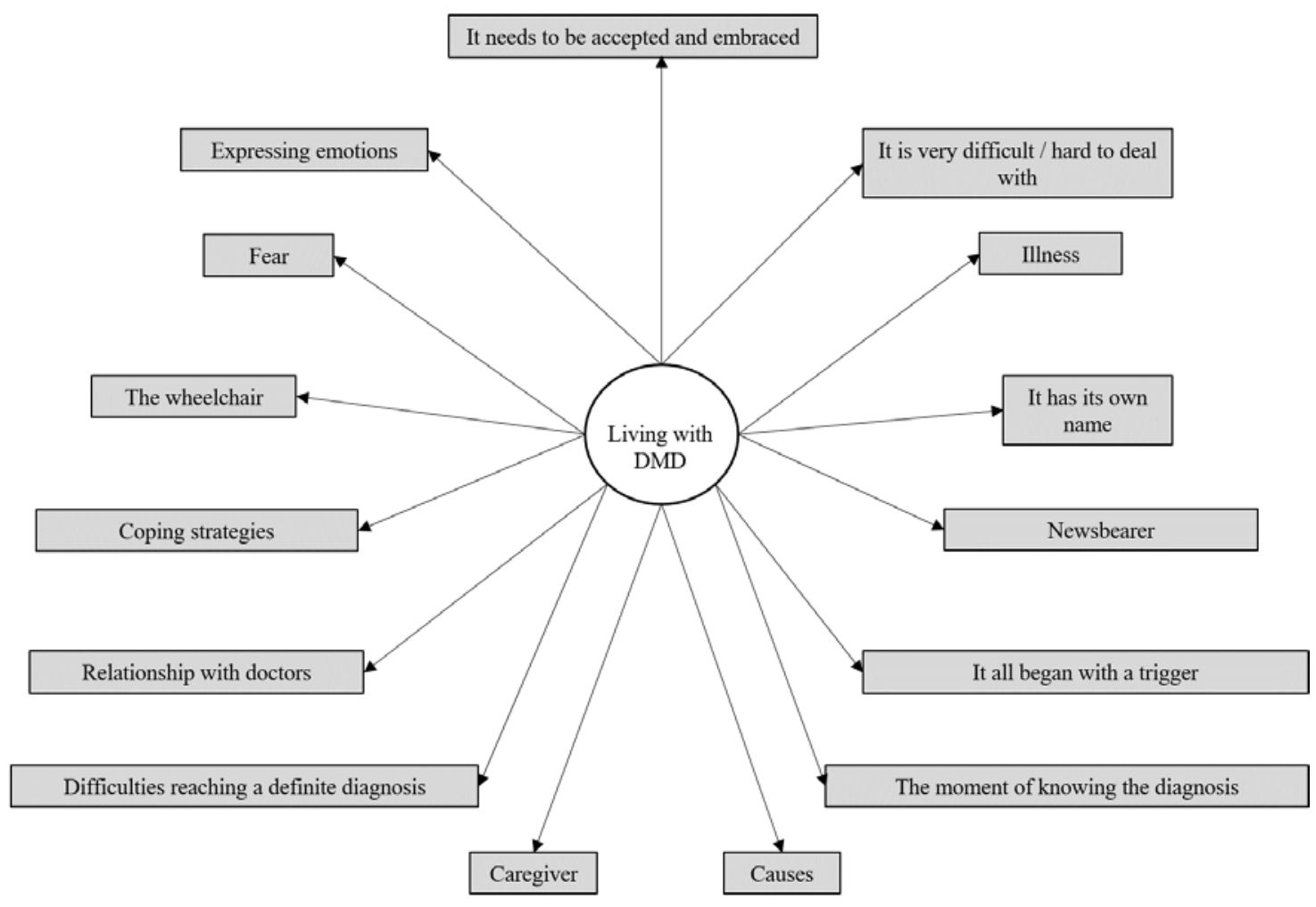

Figure 1. The experience of living with DMD

Firstly, the word "dystrophy" has been assimilated into to the patients' discourse. Participants called it "muscular dystrophy" or "Duchenne/ Duchenne's." They recalled having to cope with it since early childhood (3-5 years old) or middle childhood (7-11 years old). It was difficult for them to recall a specific moment in which they learned about the existence of the disease (Figure 2). Only two participants found difficult identifying a person as an information bearer. In contrast, most participants mentioned that their parents or a medical doctor were the information bearers (Figure 3).

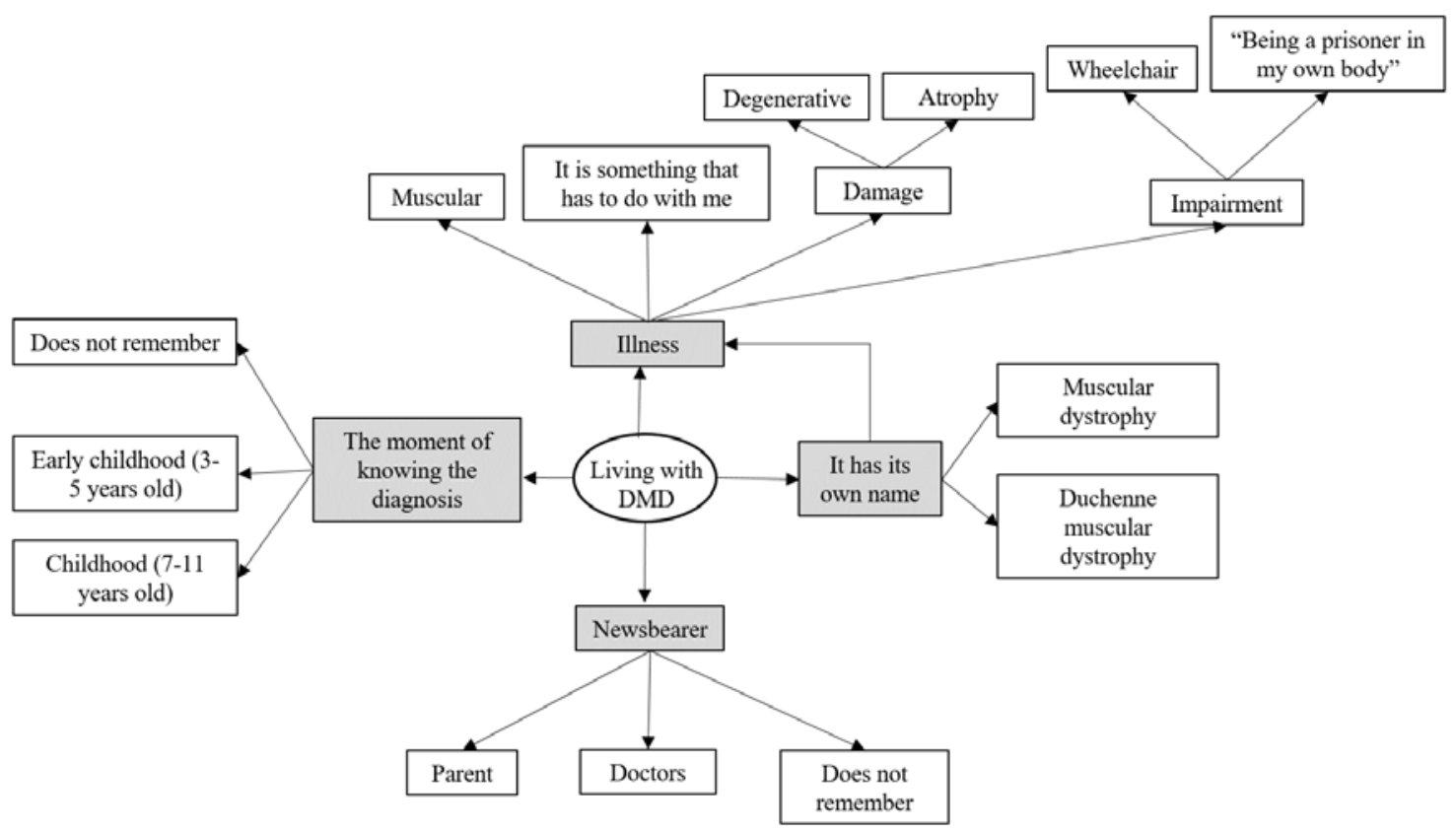

Figure 2. The experience of being diagnosed, and patients' understanding of DMD 


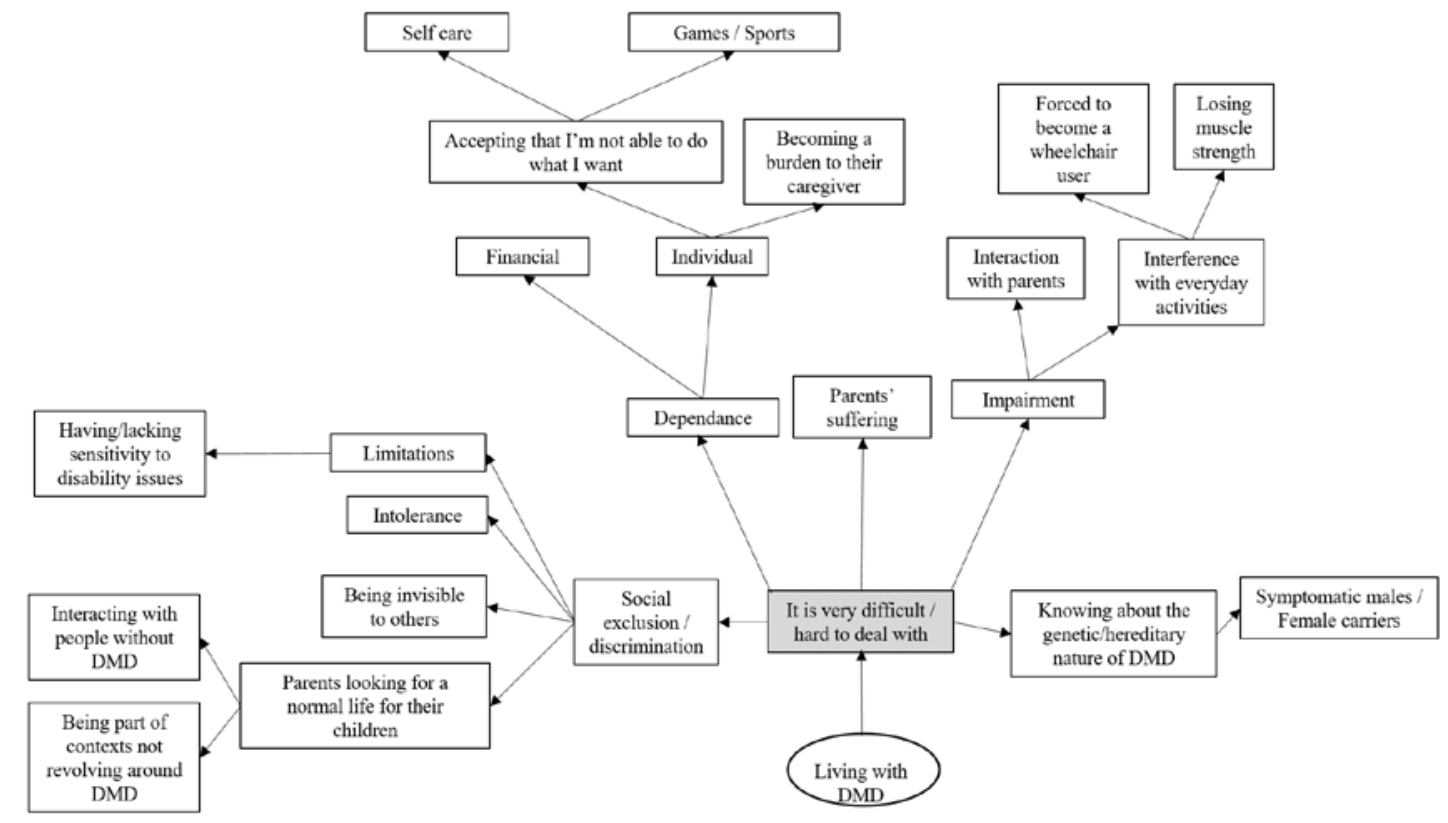

Figure 3. Bearing with the difficulties emerging from DMD

When talking about their condition, patients described DMD as a muscular disease: "it's something inside me, which has to do with me". At the same time, they acknowledged the degenerative nature of DMD, manifested in atrophy and other mobility impairments that severely deprive them from their freedom, until they eventually become wheelchair users. They said, "It is like being a prisoner in my own body" (Figure 2).

The participants' narratives made evident that living with DMD is "something very hard, very difficult". They experience their own suffering whilst also witnessing their parents' distress. Moreover, their skills to interact with peers become progressively more limited. DMD interferes with the daily life of these young people who will eventually lose all their muscular strength and find themselves forced to permanently use a wheelchair. In addition to the mobility impairments, participants describe a perception of being socially isolated and discriminated against, which translates into feelings of being 'invisible' to others or actively rejected. This context elicits a high degree of self-consciousness about the participants' own disability: "one is different compared to others; one does not have the same abilities that they have". However, boys and young men with DMD acknowledged that their parents - mostly their mothers try to create a setting in which they can live a "normal" life: one that is not centered on the disability and one in which they can integrate with people not diagnosed with the same condition or any other disabilities. (Figure 3).

Participants also expressed that DMD is a condition they have learned to accept and to deal with. For some of them, the disease is part of "God's plan", in the form of a blessing or a challenge aligned with their own personality traits: "because I am a warrior, I'll be able to overcome this". On the other hand, their appraisal contrasts with the possibility of the disease being caused by chance or determined by uncontrollable genetic issues (Figure 4).

Notably, each participant was able to recall the early manifestations of the disease. They identified a trigger event: gait disturbances, specifically "waddling" gait, and frequent falls (Figure 4). They also reported the difficulties they faced in the process of being diagnosed. All the participants were initially misdiagnosed (i.e. poliomyelitis and pes planus) and even recalled being judged by their doctors. Some participants reported that doctors said to their caregivers "The child is just lazy... spoiled" and "you have to exert some authority". Such judgements translated into further parental demands to modify some behaviors that were - unbeknownst to the children themselves and their parents - completely out of their control (Figure 4). Participants also reported that, back at the time when their condition was initially explained to them, they faced a significant psychological impact originated from understanding the genetic and hereditary nature of the disease, including the fact that males are symptomatic while females are carriers (Figure 4). They also reported that DMD implies being dependent on other people financially, and even emotionally: "DMD is a significant added expense. For example: each time we need transportation, we have to pay for a taxicab". Finally, participants reported feeling like a burden to their caregiver and they recognized many difficulties inherent to taking care of themselves (i.e. taking a shower, eating, going to the bathroom, scratching their backs) and to performing activities routinely associated with young people (i.e. playing games, sports). 


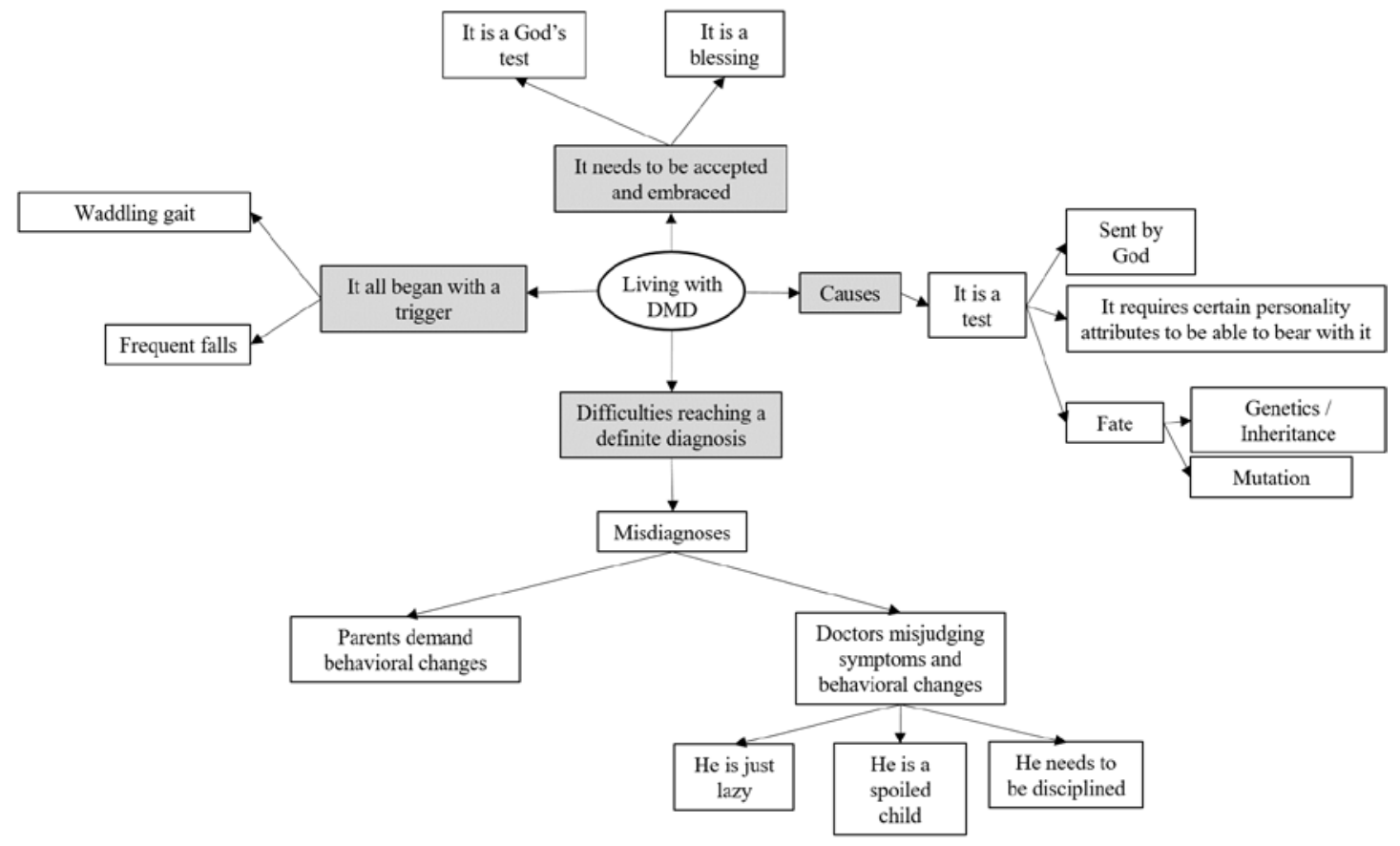

Figure 4. Dealing with initial DMD symptoms

An additional emergent topic described how participants were afraid of their own suffering: "I'm afraid of suffering more every day. Although this might sound sad, I'm not afraid of dying. In fact, I'd rather die" (P.1). They also worry about causing more suffering and distress to other people in their lives: "maybe my condition will worsen and that will put my mother in a bad situation" (P.1). In this case, an increased worry is associated with the disease progression which, in turn, leads the participants to think about how their family members are going to react when they die (Figure 5): "The truth is that I'm not that afraid of what might happen to me, but I worry about my family. For example, besides my brother, I also had a cousin who died because of this disease. So, seeing what this disease causes to other people really scares me. I'm also afraid of seeing what might happen to others who are suffering because of me" (P. 8).

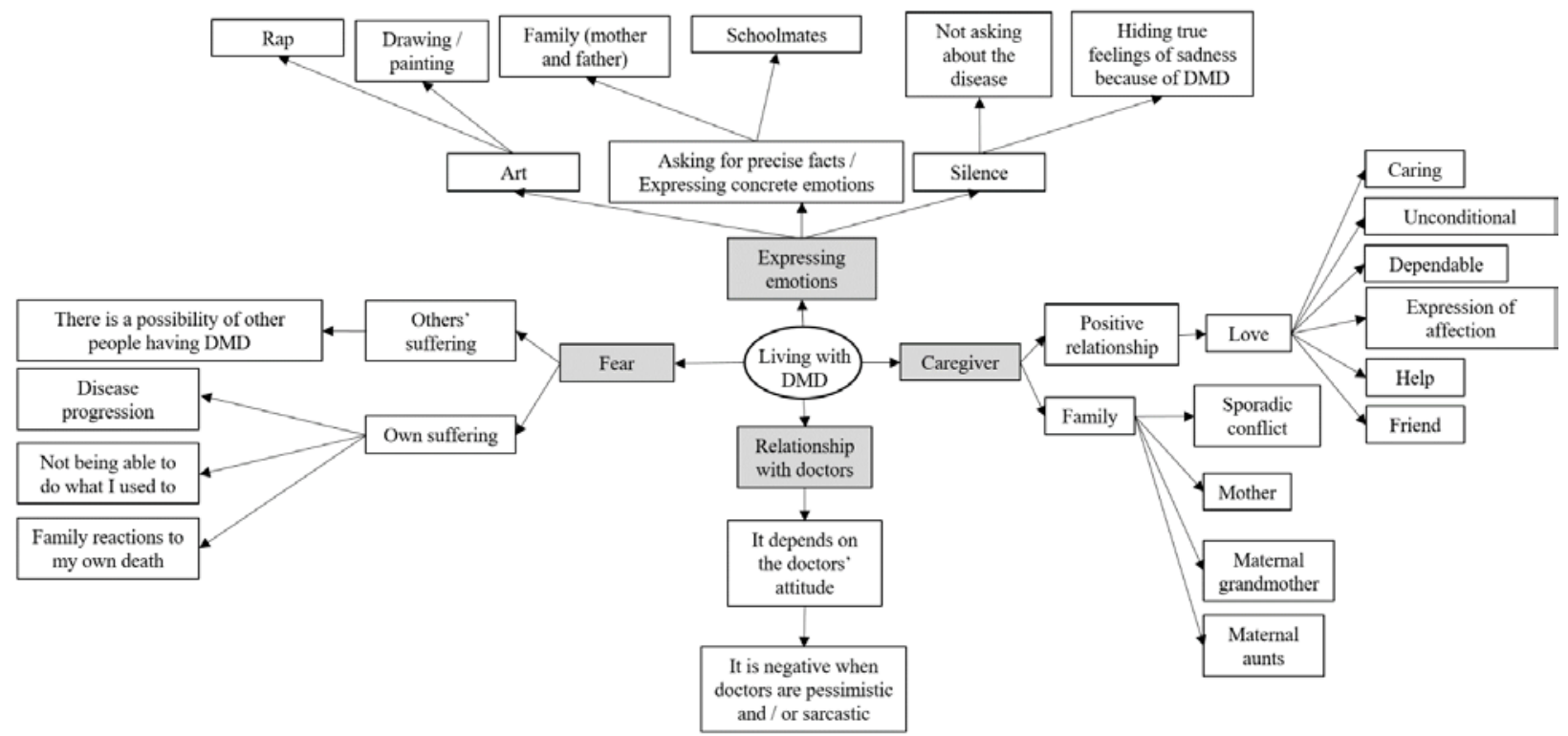

Figure 5. Emotional and interpersonal experiences associated with DMD 
All the participants had one or multiple relatives taking care of them. Generally, the mother was the main caregiver, while grandmothers and aunts - on the mothers' side contributed to caregiving when the mother was absent. Only in one case, a grandmother replaced the mother. Participants also reported having a positive relationship with their caregivers, with some eventual conflicts that they did not consider relevant. They indicated that caregiving interactions were positive, since they were based on unconditional love, trust, friendship, and expressions of affection “... my mom is always there for me. Even if she's tired, she carries me around, helps me getting dressed, bathes me... she does everything" (P.5). In most cases, participants did not report negative aspects about their caregivers and only described having sporadic arguments with them or moments of bad temper (Figure 5).

On the other hand, perceptions of boys and young men with DMD on the interactions with their doctors seem to depend on the attitudes and behaviors exhibited by the physicians. In other words, if children and adolescents perceive their doctors as pessimistic, judgmental, or blatantly indifferent, the doctor-patient relationship tends to be negatively perceived. In contrast, if they perceive their doctors as optimistic (i.e. they say things such as "you should have faith" P.2) or sensitive towards them or their caregivers, the doctor-patient relationship is perceived as positive (Figure 5).

Another emergent topic in the participants' narratives is related to the silence and keeping important things to themselves. Notably, young people with DMD reported not talking about their feelings, especially sadness or hopelessness. They also reported not talking to other people about their disease, except for inquiring on very concrete facts. In those cases, they mentioned being very careful when choosing who they talk to, usually close acquaintances, their mothers, or schoolmates. Other participants mentioned that art - music and drawing - was their way of expressing feelings related to their disease (Figure 5): "No, the truth is that I do not talk to others, but what I do is to express myself through rap, because that's the only thing that understands me" (P.1). Except for only one participant, none of them had any psychological support as part of their healthcare services. Moreover, the participant who did receive psychological services, described the experience as very negative and consisting of only one therapy session.

The wheelchair was a common and relevant topic described by the participants. Initially, they identified mostly negative appraisals throughout their personal history. In previous stages of the disease, they described themselves as feeling highly reluctant to use a wheelchair because they saw it as a crucial moment in their lives that represented the fact that - once they sat on it - they would never be able to walk again. In fact, they felt they would be trapped in it: "I was 9 years old -9 years old since I first sat on this wheelchair and will be like this forever" (P.1). The wheelchair also represents their loss of autonomy and an immense sense of vulnerability even in everyday situations: “. . . once, other children were playing and hit me with a ball... and, of course, my chair went backwards, and I fell and hit my head on the ground. I lost consciousness. When I got back home, I couldn't recognize anybody there. I felt I was going crazy. After that, my mom took me out of school and made me spend two years without any school at all" (P.7). Nonetheless, participants acknowledged that using a wheelchair is positive to some extent, especially because - by using the wheelchair their caregivers do not have to do extraordinary efforts to help them mobilizing, which otherwise they would have to. The wheelchair represents a paradox between losing and at the same time - preserving some autonomy, safety, and independence (Figure 6).

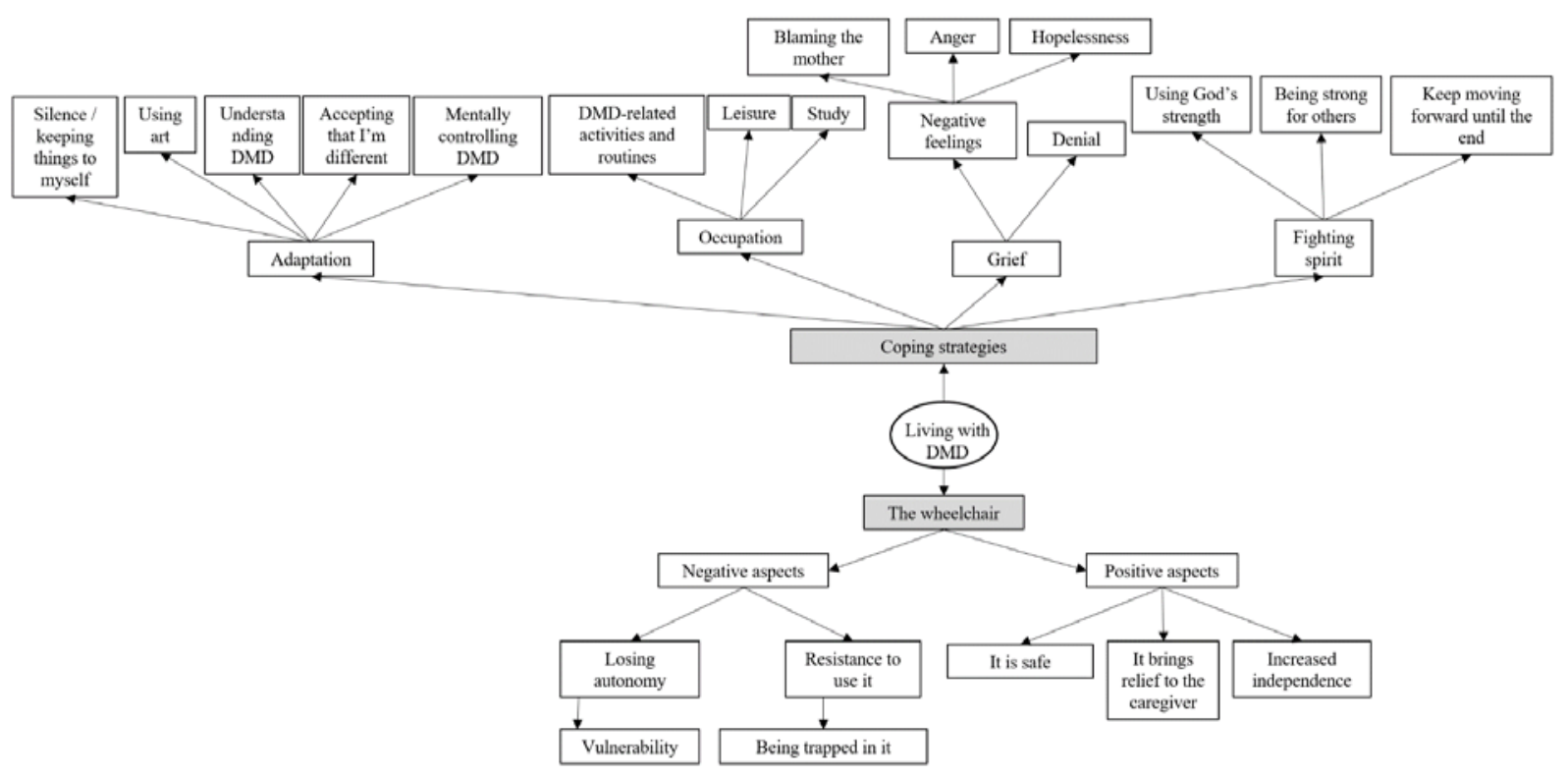

Figure 6. Becoming a wheelchair user and further coping strategies 
Throughout the many stages of the disease, participants described the development of multiple strategies to cope with DMD and its progression. Understanding the disease and radically accepting themselves as different are some of the ways to ease the burden of DMD. They also described controlling the disease "with their minds", which was a way of saying that the way they think significantly influences their feelings and behaviors. They also resort to different artistic manifestations that play the role of coping mechanisms, and protect themselves through silence, withdrawal, and discrimination among safe and unsafe contexts, so as to identify the safest one, i.e., Home. These boys and young men also occupy most of their time playing and drawing, while a few of them study. Furthermore, all of them devote significant amounts of time to illness-related activities such as physical therapies and medical appointments (Figure 6).

Notably, each participant has experienced a grieving process through stages of denial, despair, anger, frustration, and blaming their mothers for transmitting the disease: ". . . I told my mom that she was the one to blame for my disease" (P.4). However, it was also evident that their narratives described courageous expressions of coping with the disease until the very last moment, using the strength given to them by God, and never giving up (Figure 6): "Well, I have this disease because God sends illnesses to fighters, to those who can deal with them. That makes me believe that not everything is sad. Some of this is also a blessing" (P.1).

\section{Discussion}

The results of this study allow us to highlight the experiences lived by boys and young men diagnosed with DMD and the way they appraise their lives whilst coping with impairment and the proximity of death. The participants' narratives described an intense emotional experience characterized by ambivalence and an abrupt interruption of a traditional childhood and adolescence due to the need for understanding and dealing with a complex health situation. This occurs simultaneously while dealing with a new environment that demands the assimilation of a new technical - medical - language and the acceptance of a new routine filled with constant visits to the doctor and other health professionals. Additionally, participants also experience intense suffering - including anxiety, fear, sadness, and loneliness - due to the progressive loss of skills and autonomy, in addition to the corresponding consequences of disability. Finally, boys and young men strive to develop coping strategies in order to adjust to the new reality of being diagnosed with a genetic and progressive condition.

According to Réveillère (1985), it is worth noting that young people diagnosed with DMD are characterized by the way they incorporate technical and accurate words into the language they use to describe their disease and its symptoms. Such phenomenon was evidenced in this study. All the participants were able to use accurate technical language to refer to their disease and the medical procedures they were going through. The moment of diagnosis became a passage-rite to enter the world of individuals with DMD or, using Sontag's (2003) words, the kingdom of the sick, where learning a new language seems to be indicative of an ongoing adaptation to such new world.

Réveillère (1985), Latimer et al. (2017), and Birnkrant et al. (2018) have reported that young people have recurrent feelings of anxiety and sadness experienced throughout all stages of the disease, especially those that evidenced an irreversible loss of autonomy and independence - i.e. becoming a wheelchair user. In fact, our participants did report these intense feelings. Latimer et al. (2017), have also noted that anxiety and depression are common conditions reported by individuals with DMD. Furthermore, silence is also a notable element in these young people's interactions that are characterized by long pauses, nostalgic remarks, and passive accounts of experiences wherein the relentless consequences of a genetic disease are more than evident. Certainly, DMD represents a long and difficult journey that these young people and their families - most often their mothers - have faced (Latimer et al., 2017; Peay et al., 2016).

This study has also found that emotions experienced during the progressive stages of the disease were widely diverse, as Debarge et al. (2008) have also reported. Positive emotions were mostly related to courage, optimism, and hoping for the disease to stop progressing. In contrast, young people also experienced negative emotions like anxiety, stress (Colombo et al., 2017; Latimer et al., 2017; Leibowitz \& Dubowitz, 1981), suffering (Campelia \& Tate, 2019), and fear (Darmahkasih et al., 2020).

Moreover, the types, quality, and quantity of information young people receive are linked to emotionally laden experiences. Notably, our findings are congruent with those reported elsewhere (Gargiulo et al., 2008) when describing that young people diagnosed with DMD receive great amounts of information about a potential diagnosis and its prognosis. Nevertheless, recurrent misdiagnoses become associated with the caregivers' need to remain silent considering the negative emotional impact of providing information that could turn out to be inaccurate or erroneous (Gargiulo et al., 2008). In this regard, Colvin et al. (2018), have emphasized the significance of providing children with developmentally-informed services and interventions that facilitate a better understanding of the diagnosis and its prognosis, while empowering them to become active agents in the decision-making process without being completely subjected to the decisions made solely by parents or legal guardians. Complementary, authors such as Aartsma-Rus, Ginjaar and Bushby (2016) have reiterated the importance of an accurate diagnosis that enables children and their families 
to properly plan for an action course and to choose a therapeutic approach in an early stage of the disease.

It is noteworthy that the participants of this study identified their disease as an aggressive agent but did not report experiences marked by physical pain. This indicates an explicit contrast to findings reported by other researchers such as Debarge et al. (2008), Abbott and Carpenter (2015), Silva et al. (2016), and Sertpoyraz et al. (2019), who have suggested that young people diagnosed with DMD tend to describe pain as a salient element in their experiences. In the same way as proposed by Connors and Stalker (2007), young people who participated in this study described that the elements brought upon them by the disease, that were the most aggressive to them, were the physical limitations, being different from other young people, other people's attitudes, and physical barriers. Moreover, this study has shown that DMD and its concurrent impairment have altered their family dynamics and their caregivers' roles. Similar findings have also been reported elsewhere (Montalvo-Prieto et al., 2012; Montero Pardo et al., 2014; Peay et al., 2016). One notable indicator of these family role alterations is described by young people who are witnessing their caregivers' - mostly their mothers' own suffering which, in turn, leads them to choose silence as one of their coping strategies with the intention to somehow protect their mothers from more emotional pain. Recent findings reported by Turan, Ülgenalp, Memiş, Uluç and Akay Pekcanlar (2019), indicate that both, mothers and children with DMD, experience family distress resulting from anxiety and depression and their concurrent impact on their quality of life.

Negative emotional experiences also seemed to arise when young people become participants of medical research and, at the same time, are subject to misjudgments and discrimination in multiple contexts lacking in acceptance and understanding of disability. In this sense, Debarge et al. (2008) have reported that negative emotional experiences tend to intensify due to the aversive feedback young people receive from others. These authors have also described that young people with DMD tend to mention feeling ashamed. However, in this study, the young people's narrative did not communicate topics related to shame but to guilt, mostly due to the suffering and difficulties faced by their caregiver or by other significant people in their lives (Debarge et al., 2008) who are - in many cases - the sole providers of care, with no access to comprehensive support services (Skyrme, 2017). Witnessing their parents' suffering especially their mothers' - elicits anxiety in the participants. At the same time, their caregivers become overprotective (Debarge et al., 2008) which is something young people describe to understand, but they do not necessarily accept it. Therefore, this could result in potential family conflict.

According to Gargiulo et al. (2008), living with DMD is also characterized by multiple losses, which these boys and young men must cope with. For the participants of this study, gait loss and using a wheelchair were the most salient themes within their narratives. Additionally, Gargiulo et al. (2008) and Skyrme (2017) describe how boys experience severe anxiety and emotional distress throughout the progressive stages leading to gait loss. Wheelchair confinement also represents the materialization of the worries associated to complete gait loss but, paradoxically, this moment also represents the end of previous experiences associated with the fear of not being able to stand and walk again. For these reasons, boys, and young men with DMD must develop a new identity in which the waddling gait completely disappears while they become able to move, and even run, by using a wheelchair (Gargiulo et al., 2008). Recent findings reported by Vorster et al. (2019) reiterate that powered or enhanced wheelchairs are beneficial to adolescents with DMD. This type of wheelchairs fosters further independence and participation, while mitigating the limitations resulting from muscle degeneration.

Another notable aspect of our findings was that our participants' narratives tended to gravitate almost exclusively around the experience of DMD. This could be an indicator of the difficulties in adjusting to this chronic medical condition and the subsequent disability brought by the natural progression of DMD. This finding can also be analyzed based on the perspective of authors such as Dekker and De Groot (2018), who propose that the experience of living with a chronic disease requires progressive psychological adjustment manifested in at least three aspects: (1) reappraisal of acute and chronic stressors (i.e. diagnosis, symptoms, treatment elements, emotions, concerns about self-image, changes in social relationships, and uncertainty) that affect the individual's motivation; (2) elicitation of emotional (i.e. anxious or depressive mood), cognitive (i.e. worry), and behavioral responses (i.e. adherence, physical activity, eating behaviors) triggered or maintained throughout different stages of the disease and under the influence of the socio-cultural context; (3) consolidation of the individual's personal experience of living with the disease - a process mediated by individual differences, personal values, life goals, early-life experiences, and sociodemographic characteristics.

This process of psychological adjustment is also influenced by social support (Miró, Vega, Gertz, Jensen, \& Engel, 2019), participation, interpersonal relationships, and contextual conditions (Dekker \& De Groot, 2018), and it is faced by the individual (Stanton, Revenson, \& Tennen, 2007) and their families (Nabors, Liddle, Graves, Kamphaus, \& Elkins, 2019) in a dynamic and heterogeneous way in which the variables previously mentioned could converge (Helgeson \& Zajdel, 2017). Psychological adjustment may also result in the emergence of resilience and coping responses and further optimism, self-esteem, and sense of mastery (Helgeson \& Zajdel, 2017) that, in turn, could work as protectors of the individual's and the caregivers' mental health (Tesei et al., 2020). 
In contrast, our participants' narratives seem permeated by negative appraisals of themselves, with a focus on passivity, deficiencies, and limitations. This is aligned with very early accounts by authors like Dembo, Leviton and Wright (1956), in which adjustment of individuals with disabilities was traditionally conceptualized only as a passive process. We also hypothesize that negative appraisals identified in some aspects of our participants' narratives could have been influenced by a lack of acceptance of their disability and its underlying chronic disease (Moss-Morris, 2013; Andrews \& Wahl, 2018). Furthermore, our participants' narratives also seem to portray themselves as individuals in disagreement with the notion of self-sufficiency due to the many impediments they must face, along with other objective threats to their lives and life goals a phenomenon also described by Goodley, Liddiard, and Runswick-Cole (2018).

Nonetheless, adjustment to a chronic medical condition is a dynamic process. Thus, our participants' narratives described a journey navigating through stages such as denial, grief, depression, anger, and retaliation. These narratives were also characterized by a marked absence of elements of a reintegration process because such reintegration would require acceptance of progressive impairment and imminent permanent disability. Also, the transactional and interpersonal aspects of the analyzed narratives were notable elements. This was evidenced by the emotional impact that participants attributed to the way they are perceived by others. This impact is difficult to cope with and the participants were not necessarily prepared for this kind of negative social transactions. However, historical, and current findings (Livneh \& Antonak, 1997; Helgeson \& Zajdel, 2017) reaffirm the potential of individuals facing chronic illnesses and disability to develop positive attitudes towards themselves, their disability, and other people in their contexts. This aspect highlights the need for comprehensive interventions that provide support to boys and young men with DMD, and to their caregivers, during critical stages and transitions in their lives.

This study possesses limitations related to the strategies used to collect data, and the characteristics of the group of participants. Specifically, we were able to conduct only a single interview with each participant. However, due care was taken to establish rapport and conduct the research procedures in a private and safe environment that was previously known to all the participants. It is worth noting that children diagnosed with DMD have significant difficulties in discussing their feelings, thus requiring a greater number of interviews to establish a good rapport (Gargiulio et al., 2008). This difficulty in establishing good rapport was observed during this study where silence was a frequent occurrence. Gargiulio et al. (2008) have also reported a phenomenon characterized by long silences, sighing, brief answers to questions, and difficulties creating and sharing a narrative account of the participants' own private experiences. This further underscores the importance of establishing rapport with the participants, especially when considering that authors like Skyrme (2017) have reported that boys and adolescents with DMD describe having limited opportunities to talk about the issues associated with their disease and their experiences.

Moreover, as reported by Debarge et al. (2008), young people frequently bring other topics into their conversations that are not related to DMD, which also occurred during our interviews. For this reason, they were free to choose the level of detail in which they wanted to discuss their DMD-related experiences, especially because avoiding conversations on this topic has been properly acknowledged as a coping strategy (Debarge et al., 2008). In fact, authors like Abbott and Carpenter $(2014,2015)$ reported that most of the 37 children enrolled in their study chose to share their experiences without providing many details, because talking about the negative physical and emotional consequences of DMD made it difficult for them to remain optimistic about their lives. Nonetheless, our participants eventually mentioned that having someone to talk to about what was happening to them was also important, since they seldom had the opportunity of being listened. This is consistent with Abbott and Carpenter's (2014, 2015), and Skyrme's (2017) studies, wherein participants reported having limited opportunities to access emotionally safe spaces where they could speak about the impact of living with a condition like DMD, or even a complete absence of such spaces in their lives.

Access to psychological services seemed unfeasible for most of the participants. Only one of them reported having seen a psychologist and described the experience as negative. This fact draws our attention to Debarge et al. (2008) who have reported that it is necessary for boys and adolescents with DMD to express their feelings and appraisals about their present and future. The absence of psychological support for people diagnosed with DMD might even be comparable to the absence of medical support. This study has also provided additional evidence on the significant emotional toll faced by boys and young men affected by this condition. Consequently, coping with DMD requires support from a multidisciplinary team in which the psychologist could embrace the role of facilitator of adjustment to the disease and, also, a liaison between doctor, patients, and the patient's family in order to establish a functional doctor-patient relationship. In fact, according to Barbot (2008), the psychologist - as a member of a multidisciplinary team providing care for people diagnosed with neuromuscular diseases - can act as an "interpreter" of the situations. This will allow other care providers to better relate to the experiences faced by these boys and young men and their families - throughout their lifespan.

A second limitation is related to the demographic characteristics of the sample of participants. In particular, 
our sample comprised mostly children and adolescents. However, despite its rare occurrence, some individuals diagnosed with DMD might eventually become young adults, which would bring new psychological challenges associated with transitioning into adulthood. This is consistent with a study by Abbott et al. (2019) who reported that adult men with DMD were able to take part of a capacity-centered society with tenacity.

In a study conducted by Hinton, Nereo, Fee and Cyrulnik (2006) with 86 children and young men with DMD, it was reported that participants exhibited more frequent behavioral problems in social contexts than their siblings and other young people without the disease. Some results also indicated that young people with DMD exhibited behaviors that could be considered immature for their chronological age, as well as deficient interpersonal relationships with peers. These difficulties included attaching exclusively to adults, complaining about being lonely, refusing to be left alone with other children, feeling jealous of other young people, easily feeling hurt, feeling disliked by other young people, having speech impairments, or preferring to be in the company of younger children (Hinton et al., 2006). In our study, we also found that the level of interaction of the participants with their peers was described as minimal by them and by their caregivers. Social isolation was also a commonly described theme. As expected, they mentioned a preference for interacting with adult relatives, their siblings and, if possible, with younger children.

Moreover, the participants' support network was mostly comprised of their primary caregiver, in most cases the mother, or other female relatives who provide care when the mother is absent or unable to do so. In this regard, Longo-Araújo de Melo and Moreno-Valdés (2007) conducted a study with 14 boys and young men with DMD and found that family support was associated with a perception of increased quality of life. On the other hand, the participants' support network of healthcare providers was fragile due to particularities of the health and social security systems in Colombia. This particularity hindered access to a stable group of health professionals over time. Therefore, the functioning of the local health and social security system in this country poses significant barriers for achieving a good quality of life, which is an aspect also highlighted by Debarge et al. (2008). These authors mentioned that young people with neuromuscular diseases like DMD should have access to a support network comprising formal and informal caregivers and care providers. Each network must be tailored to the needs of each child to strengthen the link between all the actors involved in providing care and health services (Debarge et al., 2008).

A third limitation is derived from the demographic diversity of the participants of this study, namely, age differences. This is relevant because each participant was at a different developmental stage that, in turn, cannot be equaled to the development stages of children and adolescents without DMD. Moreover, other psychosocial variables (i.e. socio-economic differences, length of previous schooling) have also been hypothesized to affect human development. Certainly, the age of our participants could have had an effect on their responses during the interview that was not considered (i.e.: transitioning from childhood to adolescence, or from adolescence to early adulthood). However, their responses and the subsequent categories and descriptors obtained through data analysis did not suggest such differences.

As described by the literature on age differences and interviewing with children, we agree with findings reported by Krähenbühl and Blades (2006) who indicate that the questions could be understood differently by each participant on the basis of style and wording, therefore affecting their responses during the interview. Considering that our study was based on a semi-structured interview with pre-established questions, this issue cannot be overlooked. However, the interviewers were allowed to introduce prompts, or other complementary verbal interventions, to facilitate the interaction and a developmentally appropriate conversation whenever possible.

A final element of discussion is related to the highly medicalized experience reported by our participants, that is, their daily routines are almost exclusively centered on constant visits to medical doctors and health professionals, physical therapy sessions, hospitalizations, complying with prescriptions, among other challenging and demanding activities. However, such activities could be used as opportunities to promote a better adjustment and adaptation to the disease and disability. This is possible by providing boys and young men with emotional, cognitive, behavioral, and social resources intended for strengthening them before a complete disability emerges. Moreover, the progressive nature of DMD also allows for development of educational interventions directed towards patients and caregivers, in which coping and social skills can be trained. Additionally, parents and caregivers could benefit from interventions for developing parenting or responsive caregiving skills. Therefore, there is a clear need for social interventions aimed to foster a more compassionate and inclusive environment for boys and young men with DMD.

In summary, this study allowed us to get closer and better relate to the experiences faced by boys and young men diagnosed with DMD in a developing nation where disability and chronic illnesses represent substantial economic and social hardships. This scenario is experienced by boys and young men with DMD who must also face several transitions along the imminent progression of the disease. Their contexts and routines become estranged, while the ideas of themselves and their future are forcibly changed. All of this happens in the company of their caregivers most often, the mother - who become permanently engaged with the task of providing care for their children whilst seeking access to healthcare in the local context by means of several persistent efforts, including legal actions. In the end, boys and young men with DMD become mindful of the fact that each symptom is an indicator of a disease that keeps progressing and leading them to a complete dependence on others and, eventually, to their own death. 


\section{A experiência dos meninos e jovens colombianos que vivem com distrofia muscular de Duchenne}

Resumo: A distrofia muscular de Duchenne (DMD) é uma doença crônica que afeta principalmente os homens, caracterizada pelo deterioro físico progressivo e por conduzir à morte. Este estudo qualitativo teve como objetivo a exploração e a compreensão da experiência do diagnóstico e da doença em jovens com DMD residentes em Bogotá, Colômbia. Após a aprovação do Comitê de Ética em Pesquisa (CEI-ABN026-000311), nove participantes participaram numa entrevista semiestruturada e as suas narrativas foram analisadas através da análise temática. Os principais temas abordados foram: a representação negativa da doença; o medo; a dificuldade em expressar emoções; a relação paciente-médico; a cadeira de rodas; os cuidadores e as estratégias de resiliência. Concluímos que os jovens afetados pela DMD enfrentam experiências desafiantes que evidenciam a necessidade de interações melhores, mais respeitosas e compassivas com os profissionais de saúde. Ao mesmo tempo, as suas experiências são indicativas de um contexto sociocultural que precisa de se tornar mais recetivo e compassivo para com os jovens e as deficiências.

Palavras-chave: distrofia muscular de Duchenne, crianças, adolescentes, psicologia, aspetos psicossociais.

\section{L'expérience des garçons et des jeunes hommes colombiens vivant avec dystrophie musculaire de Duchenne}

Résumé: La Dystrophie Musculaire de Duchenne (DMD) est une maladie chronique qui touche principalement les hommes et se caractérise par détérioration physique progressive et, éventuellement, la mort. Cette rechérche qualitative a explorer l'expérience du diagnostic et de la maladie chez les jeunes atteints de DMD à Bogotá, Colombie. Cette rechérche a été évaluée et approuvée par un comité d'éthique de la recherche (CEI-ABN026-000311). Neuf jeunes ont participé à un entretien semi-structuré et leurs récits ont été analysés à l'aide d'une analyse thématique. Les principaux thèmes développés dans les récits étaient: la représentation négative de la maladie; peur; difficulté à exprimer ses émotions; la relation médecin-patient; le fauteuil roulant; soignants et stratégies d'adaptation. Nous concluons que les jeunes touchés par la DMD vivent de multiples expériences difficiles qui mettent en évidence la nécessité d'interactions plus respectueuses et plus compatissantes avec les prestataires de services de santé. En même temps, leurs expériences montrent un contexte socioculturel qui doit être plus sensible et compatissant envers les enfants et les jeunes handicapés.

Mots-clés: dystrophie musculaire de Duchenne, enfants, adolescents, psychologie, aspects psychosociaux.

\section{La experiencia de niños y jóvenes colombianos que viven con distrofia muscular de Duchenne}

Resumen: La distrofia muscular de Duchenne (DMD) es una enfermedad crónica que afecta principalmente a hombres y se caracteriza por deterioro físico progresivo y, eventualmente, la muerte. Este estudio cualitativo buscó explorar y comprender la experiencia del diagnóstico y la enfermedad en jóvenes con DMD en la ciudad de Bogotá, Colombia. Tras recibir autorización del Comité de Ética en Investigación (CEI-ABN026-000311), nueve participantes colaboraron con una entrevista semiestructurada y sus narrativas fueron analizadas usando análisis temático. Los principales temas desarrollados en las narrativas fueron: representación negativa de la enfermedad; miedo; dificultad expresando emociones; la relación médico-paciente; la silla de ruedas; los cuidadores y las estrategias de afrontamiento. Concluimos que los jóvenes afectados por la DMD enfrentan múltiples experiencias retadoras que hacen evidente la necesidad de interacciones más respetuosas y compasivas con los proveedores de servicios de salud. Al mismo tiempo, sus experiencias muestran un contexto sociocultural que necesita ser más sensible y compasivo con los niños y jóvenes en situación de discapacidad.

Palabras claves: distrofia muscular de Duchenne, niños, adolescentes, psicología, aspectos psicosociales.

\section{References}

Aartsma-Rus, A., Ginjaar, I. B., \& Bushby, K. (2016). The importance of genetic diagnosis for Duchenne muscular dystrophy. Journal of Medical Genetics, 53(3), 145-151. doi: 10.1136/jmedgenet-2015-103387

Abbott, D. \& Carpenter, J. (2014). "Wasting precious time": young men with Duchenne muscular dystrophy negotiate the transition to adulthood. Disability \& Society, 29(8),1192-1205. doi: 10.1080/09687599.2014.916607
Abbott, D. \& Carpenter, J. (2015). "The things that are inside of you are horrible": children and young men with Duchenne muscular dystrophy talk about the impact of living with a long-term condition. Child Care in Practice, 21(1), 67-77. doi: 10.1080/13575279.2014.97722

Abbott, D., Carpenter, J., Gibson, B. E., Hastie, J., Jepson, M., \& Smith, B. (2019). Disabled men with muscular dystrophy negotiate gender. Disability \& Society, 34(5), 683-703. doi: 10.1080/09687599.2019.1584093 
Andrews, J. G., \& Wahl, R. A. (2018). Duchenne and Becker muscular dystrophy in adolescents: current perspectives. Adolescent Health, Medicine and Therapeutics, 9, 53-63. doi: 10.2147/AHMT.S125739

Barbot, F. (2008). Le travail du psychologue dans les consultations pluridisciplinaires en maladies neuromusculaires. Neuropsychiatrie de l'Enfance et de l'Adolescence, 56(2), 89-94. doi: 10.1016/j.neurenf.2007.11.011

Birnkrant, D. J., Bushby, K., Bann, C. M., Apkon, S. D., Blackwell, A., Colvin, M., . . . Ward, L. M. (2018). Diagnosis and management of Duchenne muscular dystrophy, part 3: primary care, emergency management, psychosocial care, and transitions of care across the lifespan. The Lancet Neurology, 17(5), 445-455. doi: 10.1016/S1474-4422(18)30026-7

Braun, V., \& Clarke, V. (2006). Using thematic analysis in psychology. Qualitative Research in Psychology, 3(2), 77-101. doi: 10.1191/1478088706qp063oa

Campelia, G., \& Tate, T. (2019). Empathetic practice: The struggle and virtue of empathizing with a patient's suffering. Hastings Center Report, 49(2), 17-25. doi: $10.1002 /$ hast.989

Chamberlain, K., \& Murray, M. (2017). Qualitative research in health psychology. In C. Willig, \& W. S. Rogers (Eds.), The SAGE handbook of qualitative research in psychology (pp. 431-449). London: Sage.

Colombo, P., Nobile, M., Tesei, A., Civati, F., Gandossini, S., Mani, E., . . . D'Angelo, G. (2017). Assessing mental health in boys with Duchenne muscular dystrophy: Emotional, behavioural and neurodevelopmental profile in an Italian clinical sample. European Journal of Paediatric Neurology, 21(4), 639-647. doi: 10.1016/j.ejpn.2017.02.007

Colvin, M. K., Poysky, J., Kinnett, K., Damiani, M., Gibbons, M., Hoskin, J., . . . Weidner, N. (2018). Psychosocial management of the patient with Duchenne muscular dystrophy. Pediatrics, 142(Pt. 2), 99-109. doi: 10.1542/peds.2018-0333L

Connors, C., \& Stalker, K. (2007). Children's experiences of disability: Pointers to a social model of childhood disability. Disability \& Society, 22(1), 19-33. doi: 10.1080/09687590601056162

Crisafulli, S., Sultana, J., Fontana, A., Salvo, F., Messina, S., \& Trifirò, G. (2020). Global epidemiology of Duchenne muscular dystrophy: An updated systematic review and meta-analysis. Orphanet Journal of Rare Diseases, 15, 1-20. doi: 10.1186/s13023-020-01430-8

Crivello, M. C. (2013). Implicancias y consecuencias de la enfermedad crónica sobre el grupo familiar. Revista Virtual de la Facultad de Psicología y Psicopedagogía de la Universidad del Salvador, 30, 24-36. Retrieved from https://bit.ly/39wxJfL

Darmahkasih, A. J., Rybalsky, I., Tian, C., Shellenbarger, K. C., Horn, P. S., Lambert, J. T., \& Wong, B. L. (2020). Neurodevelopmental, behavioral, and emotional symptoms common in Duchenne muscular dystrophy. Muscle \& Nerve, 61(4), 466-474. doi: 10.1002/mus.26803
Debarge, S., Delion, P., Cuisset, J. -M., \& Réveillère, C. (2008). Maladies neuromusculaires et souffrance psychique chez l'enfant, sa famille et les soignants. Neuropsychiatrie de l'Enfance et de l'Adolescence, 56(2), 58-62. doi: 10.1016/neurenf.2007.06.011

Dekker, J. \& De Groot, V. (2018). Psychological adjustment to chronic disease and rehabilitation: An exploration. Disability and Rehabilitation, 40(1), 116-120. doi: 10.1080/09638288.2016.1247469

Dembo, T., Leviton, G., \& Wright, B. A. (1956). Adjustment to misfortune: A problem of social psychological rehabilitation. Artificial Limbs, 3(2), 4-62. Retrieved from https://bit.ly/3ob9Hew

Desguerre, I., \& Laugel, V. (2015). Diagnostic et histoire naturelle de la dystrophie musculaire de Duchenne. Archives de Pédiatrie, 22(12, Pt. 1), 24-30. doi: 10.1016/S0929-693X(16)30005-7

Di Filippo, T., Parisi, L., \& Roccella, M. (2012). Psychological aspects in children affected by Duchenne de Boulogne muscular dystrophy. Mental Illness, 4(5), 21-24. doi:10.4081/mi.2012.e5

Fraser, H. G., Redmond, R. Z., \& Scotcher, D. F. (2018). Experiences of women who have had carrier testing for Duchenne muscular dystrophy and Becker muscular dystrophy during adolescence. Journal of Genetic Counseling, 27(6), 1349-1359. doi: 10.1007/s10897-018-0266-0

Fusch, P. I., \& Ness, L. R. (2015). Are we there yet? Data saturation in qualitative research. The Qualitative Report, 20(9), 1408-1416. Retrieved from https://bit.ly/36tcidL

Gargiulo, M., Angeard, N., Herson, A., Fosse, S., Themar Noël, C., Jacquette, A., Eymarda, B., Heron, D., \& Mazet, P. (2008). Impact psychologique de la maladie de Duchenne sur l'enfant et l'adolescent, ses parents, sa fratrie. Onze années d'expérience d'une consultation pluridisciplinaire. Neuropsychiatrie de l'Enfance et de l'Adolescence, 56(2), 73-81. doi: 10.1016/j.neurenf.2008.01.011

Genetic and Rare Diseases Information Center. (2020). Duchenne muscular dystrophy. Retrieved from https://bit.ly/2JDjlr6

Giliberto, F., Radic, C.P., Luce, L., Ferreiro, V., De Brasi, C., \& Szijan, I. (2014). Symptomatic female carriers of Duchenne muscular dystrophy (DMD): Genetic and clinical characterization. Journal of the Neurological Sciences, 336(1-2), 36-41. doi: 10.1016/j.jns.2013.09.036

Gocheva, V., Schmidt, S., Orsini, A. -L., Hafner, P., Schaedelin, S., Weber, P. \& Fischer, D. (2019). Psychosocial adjustment and parental stress in Duchenne Muscular Dystrophy. European Journal of Pediatric Neurology, 23(6), 832-841. doi: 10.1016/j.ejpn.2019.09.008

Goodley, D., Liddiard, K., \& Runswick-Cole, K. (2018). Feeling disability: Theories of affect and critical disability studies. Disability \& Society, 33(2), 197-217. doi: 10.1080/09687599.2017.1402752

Helgeson, V. S., \& Zajdel, M. (2017). Adjusting to chronic health conditions. Annual Review of Psychology, 68, 545-571. doi: 10.1146/annurev-psych-010416-044014 
Hinton, V. J., Nereo, N. E., Fee, R. J., \& Cyrulnik, S. E. (2006). Social behavior problems in boys with Duchenne muscular dystrophy. Developmental and Behavioral Pediatrics, 27(6), 470-476. doi: 10.1097/00004703-200612000-00003

Krähenbühl, S., \& Blades, M. (2006). The effect of interviewing techniques on young children's responses to questions. Child: Care, Health and Development, 32(3), 321-331. doi: 10.1111/j.1365-2214.2006.00608.x

Landfeldt, E., Thompson, R., Sejersen, T., McMillan, H. J., Kirschner, J., \& Lochmüller, H. (2020). Life expectancy at birth in Duchenne muscular dystrophy: a systematic review and meta-analysis. European Journal of Epidemiology, 35, 643-653. doi: 10.1007/s10654-020-00613-8

Latimer, R., Street, N., Conway, K. C., James, K., Cunniff, C., Oleszek, J., . . . Paramsothy, P. (2017). Secondary conditions among males with Duchenne or Becker muscular dystrophy. Journal of Child Neurology, 32(7), 663-670. doi: 10.1177/0883073817701368

Leibowitz, D., \& Dubowitz, V. (1981). Intellect and behaviour in Duchenne muscular dystrophy. Developmental Medicine and Child Neurology, 23(6), 577-590. doi: 10.1111/j.1469-8749.1981.tb02039.x

Livneh, H., \& Antonak, R. F. (1997). Psychosocial Adaptation to Chronic Illness and Disability. Gaithersburg, MD: Aspen.

Longo-Araújo de Melo, E., \& Moreno-Valdés, M. T. (2007). Evaluación de la calidad de vida de los niños con distrofia muscular progresiva de Duchenne. Revista de Neurología, 45(2), 81-87. doi: 10.33588/rn.4502.2007055

Miró, J., Vega, R., Gertz, K. J., Jensen, M. P., \& Engel, J. M. (2019). The role of perceived family social support and parental solicitous responses in adjustment to bothersome pain in young people with physical disabilities. Disability and Rehabilitation, 41(6), 641-648. doi: 10.1080/09638288.2017.1400594

Montalvo-Prieto, A. A., Cabrera-Nanclares, B., \& Quiñones-Arrieta, S. (2012). Enfermedad crónica y sufrimiento: revisión de literatura. Aquichan, 12(2), 134-143. doi: 10.5294/aqui.2012.12.2.4

Montero Pardo, X. M., Jurado Cárdenas, S. J., \& Méndez Venegas, J. M. (2014). Carga, ansiedad y depresión en cuidadores primarios informales de niños con cáncer. Psicología y Salud, 24(1), 45-53. Retrieved from https://bit.ly/2K7kR59

Moss-Morris, R. (2013). Adjusting to chronic illness: time for a unified theory. British Journal of Health Psychology, 18(4), 681-686. doi: 10.1111/bjhp.12072

Murray, M., \& Chamberlain, K. (1999). Qualitative health psychology: theories and methods. London: Sage.

Nabors, L., Liddle, M., Graves, M. L., Kamphaus, A., \& Elkins, J. (2019). A family affair: supporting children with chronic illnesses. Child: Care, Health and Development, 45(2), 227-233. doi: 10.1111/cch.12635
Nereo, N. E., Fee, R. J., \& Hinton, V. J. (2003). Parental stress in mothers of boys with Duchenne muscular dystrophy. Journal of Pediatric Psychology, 28(7), 473-484. doi: 10.1093/jpepsy/jsg038

Nereo, N. E., \& Hinton, V. J. (2003). Three wishes and psychological functioning in boys with Duchenne muscular dystrophy. Journal of Developmental \& Behavioral Pediatrics, 24(2), 96-103. doi: 10.1097/00004703-200304000-00004

Orphanet. (2012). About rare diseases. Retrieved from https://bit.ly/3pF2a9t

Peay, H. L., Meiser, B., Kinnett, K., Furlong, P., Porter, K., \& Tibben, A. (2016). Mothers' psychological adaptation to Duchenne/Becker muscular dystrophy. European Journal of Human Genetics, 24, 633-637. doi: 10.1038/ejhg.2015.189

Rall, S., \& Grimm, T. (2012). Survival in Duchenne muscular dystrophy. Acta Myologica, 31(2), 117-120. Retrieved from https://bit.ly/37Ipw5L

Réveillère, C. (1985). Colloque sur les myopathies. Brussels: Les Petites Abeilles.

Riger, S., \& Sigurvinsdottir, R. (2016). Thematic analysis. In L. A. Jason \& D. S. Glenwick (Eds.), Handbook of methodological approaches to community-based research: Qualitative, quantitative, and mixed methods (pp. 33-41). Oxford. doi: 10.1093/med:psych/9780190243654.003.0004

Sandelowski, M. J. (2008). Justifying qualitative research. Research in Nursing \& Health, 31(3), 193-195. doi: 10.1002/nur.20272

Sertpoyraz, F. M., Tiftikcioglu, B. I., Baydan, F., Tuncay, B., Gunduz, N. E., Dikici, A., \& Zorlu, Y. (2019). Relationship of scoliosis with pain and respiratory dysfunction in patients with Duchenne muscular dystrophy. Journal of Pediatric Neurology, 18(4), 185-189. doi: 10.1055/s-0039-3400971

Silva, T. D., Massetti, T., Monteiro, C. B. M., Trevizan, I. L., Arab, C., Caromano, F. A., . . . Favero, F. M. (2016). Pain characterization in Duchenne muscular dystrophy. Arquivos de Neuro-Psiquiatria, 74(9), 767-774. doi: 10.1590/0004-282X20160107

Sim, J., Saunders, B., Waterfield, J., \& Kingstone, T. (2018). Can sample size in qualitative research be determined a priori? International Journal of Social Research Methodology, 21(5), 619-634. doi: 10.1080/13645579.2018.1454643

Skyrme, S. (2017). In and on their own terms: children and young people's accounts of life with Duchenne muscular dystrophy. Child Care in Practice, 23(1), 77-89. doi: 10.1080/13575279.2016.1158152

Sontag, S. (2003). Regarding the pain of others. New York, NY: Picador.

Stanton, A. L., Revenson, T. A., \& Tennen, H. (2007). Health psychology: psychological adjustment to chronic disease. Annual Review of Psychology, 58, 565-592. doi: 10.1146/annurev.psych.58.110405.085615 
Tesei, A., Nobile, M., Colombo, P., Civati, F., Gandossini, S., Mani, E., . . . D’Angelo, G. (2020). Mental health and coping strategies in families of children and young adults with muscular dystrophies. Journal of Neurology, 267, 2054-2069. doi: 10.1007/s00415-020-09792-6

Turan, S., Ülgenalp, A., Memiş, H., Uluç, Y., \& Akay Pekcanlar, A. (2019). Family functioning and child behavioral problems with Duchenne/Becker muscular dystrophy: a cross-sectional study. Journal of Surgery and Medicine, 3(7), 515-519. doi: 10.28982/josam.593412

Urquhart, C. (2013). Grounded theory for qualitative research: a practical guide. Thousand Oaks, CA: Sage.

Velázquez Pérez, Y., \& Espín Andrade, C. A. M. (2014). Repercusión psicosocial y carga en el cuidador informal de personas con insuficiencia renal crónica terminal. Revista Cubana de Salud Pública, 40(1), 3-17. Retrieved from https://bit.ly/37qiTov
Vorster, N., Evans, K., Murphy, N., Kava, M., Cairns, A., Clarke, D., . . . Downs, J. (2019). Powered standing wheelchairs promote independence, health and community involvement in adolescents with Duchenne muscular dystrophy. Neuromuscular Disorders, 29(3), 221-230. doi: 10.1016/j.nmd.2019.01.010

Yamaguchi, M., Sonoda, E., \& Suzuki, M.(2017). The experience of parents of adult sons with Duchenne muscular dystrophy regarding their prolonged roles as primary caregivers: a serial qualitative study. Disability and Rehabilitation, 41(7), 746-752. doi: 10.1080/09638288.2017.1408148

Received: $12 / 10 / 2019$

Reviewed: 09/28/2020

Approved: 11/06/2020 